\title{
The theory of some asymptotic fixed point theorems
}

\author{
ANTON S. MUREŞAN
}

\section{ABSTRACT.}

In this paper we present the theory about some fixed point theorems for convex contraction mappings. We give some results on data dependence of fixed points, on sequences of operators and fixed points, on well-possedness of fixed point problem, on limit shadowing property and on Ulam-Hyers stability for equations of fixed points.

\section{REFERENCES}

[1] Andras, Sz., Fredholm-Volterra integral equations, Ed. Did. Ped., București, 2005 (In Romanian)

[2] Browder, F. E., On a generalization of the Schauder fixed point theorem, Duke Math. J., 26 (1959), 291-303

[3] Browder, F. E. (ed), Mathematical Developments Arising from Hilbert Problems, Proc. Symp. in Pure Math., Amer. Math. Soc., Vol. 18, (1976)

[4] Browder, F. E., Nonlinear operators and nonlinear equations of evolution in Banach spaces, Proc. Symp. Pure Math., Amer. Math. Soc., Vol. 18, (1976)

[5] Filip, A. D., Fixed point theorems in Kasahara spaces with respect to an operator and applications, Fixed Point Theory, 12 (2011), No. 2, 329-340

[6] Istrățescu, V. I., Fixed point theorems for convex contraction mappings and convex nonexpansive mappings, Libertas Mathematica, I (1981), 151-165

[7] Horn, W. A., Some fixed point theorems for compact maps and flows in Banach spaces, Trans. Amer. Math. Soc., 149 (1970), 391-404

[8] Mureşan, A. S., Graphic contractions, Proceedings - ICFPTA, Cluj-Napoca, July 2012, 191-200

[9] Mureşan, V., Functional-Integral Equations, Mediamira, Cluj-Napoca, 2003

[10] Mureşan, V., Ulam stability of a functional-integral equation with linear modification of the argument, Proceedings of the 12-th International Conference APLIMAT 2013 Bratislava, February 5-7, 2013, P49-7p

[11] Nussbaum, R. D., The fixed point index and fixed point theorems for $k$-set-contractions, Ph.D. Dissertation, Univ. of Chicago, 1969

[12] Nussbaum, R. D., Some asymptotic fixed point theorems, Trans. Amer. Math.Soc., 171 (1972), 349-375

[13] Nussbaum, R. D., On the uniqueness of the topological degree for k-set-contractions, Math. Z., 137 (1974), 1-6

[14] Păcurar, M., Fixed point theory for cyclic Berinde operators, Fixed Point Theory, 12 (2011), No. 2, 419-428

[15] Păcurar, M. and Rus, I. A., Fixed point theory for cyclic $\varphi$-contractions, Nonlinear Analysis, 72 (2010), $1181-1187$

[16] Rus, I. A., Maps with $\varphi$-contractive iterates,Studia Univ. Babeş-Bolyai, Mathematica, XXV, 4, 1980, 47-51 (in Romanian)

[17] Rus, I. A., Picard operators and applications,Scientiae Math. Jpn, 58 (2003), No.1, 191-219

[18] Rus, I. A., The theory of a metrical fixed point theorem: theoretical and applicative relevances, Fixed Point Theory, 9 (2004), No. 2, 541-559

[19] Rus, I. A., Some nonlinear functional differential and integral equations, via weakly Picard operator theory: a survey, Carpathian J. Math., 26 (2010), 230-258

[20] Rus, I. A., Petruşel, A. and Petruşel, G., Fixed point theory, Cluj University Press, Cluj-Napoca, 2008

[21] Shegal, V. M., A fixed point theorem for mappings with contractive iterate, Proc. Amer. Math. Soc., 23 (1969), 631-634

Received: 06.10.2013; In revised form: 24.03.2014; Accepted: 20.10.2014

2010 Mathematics Subject Classification. 47H10, 54H25.

Key words and phrases. Fixed point, Picard operator, weakly Picard operator, Bessaga operator, Janos operator, data dependence, sequences of operators and fixed points, well-possedness problem, limit shadowing property, Ulam stability. 
BABEŞ-BOLYAI UNIVERSITY

FACULTY OF ECONOMIC SCIENCES AND BUSINESS ADMINISTRATION

DePARTMENT OF STATISTICS, ForECASTS AND MATHEMATICS

T. Mihali Street, No. 58-60, 400591 Cluj-Napoca, Romania

E-mail address: anton. muresan@econ.ubbcluj.ro 